\title{
Photophysical properties of two novel tetraphenylporphyrins substituted by guanidiniocarbonyl and monocyclic guanidine groups
}

\author{
Pavel Kubát, ${ }^{1, \dagger}$ Kamil Lang, ${ }^{2}$ Vladimír Král, ${ }^{3}$ and Franz P. Schmidtchen ${ }^{4}$ \\ ${ }^{1}$ J. Heyrovský Institute of Physical Chemistry, Academy of Sciences of the Czech Republic, Dolejškova 3, \\ 18223 Praha 8, Czech Republic \\ ${ }^{2}$ Institute of Inorganic Chemistry, Academy of Sciences of the Czech Republic, 25068 Rež, Czech Republic \\ ${ }^{3}$ Prague Institute of Chemical Technology, Technická 5, 16628 Praha 6, Czech Republic \\ ${ }^{4}$ Department of Organic Chemistry and Biochemistry, Technical University, München, D-85747 Garching,
} Lichtenberg Strasse 5, Germany

\begin{abstract}
Photophysical properties of two novel guanidiniocarbonyl (I) and monocyclic guanidine (II) tetraphenylporphyrins and their interaction with DNA were investigated by steady-state and time-resolved absorption and emission spectroscopies. I stays predominantly monomeric in aqueous solutions. It produces singlet oxygen with high quantum yield $\left(\Phi_{\Delta}=0.67\right)$ that is typical for monomeric porphyrins. The electronic absorption spectra of I are not influenced by interaction with DNA. This is in contrast with monomeric tetratolylporphyrins bearing phosphonium, ammonium and pyridinium groups where the formation of stable complexes with DNA is accompanied by a characteristic red shift of the Soret band. II extensively forms $\mathrm{H}-$ and J-aggregates, which do not produce singlet oxygen $\left(\Phi_{\Delta}<0.01\right)$. In the presence of DNA only a small fraction of II remains in monomeric form that is bound to DNA exterior.
\end{abstract}

\section{INTRODUCTION}

Reactions sensitized by porphyrins and their derivatives are widely used in photodynamic therapy (PDT) for destruction of biopolymers in cancer cells [1]. The main principle of PDT is formation of cytotoxic species (singlet oxygen, triplet states of porphyrin) resulting from irradiation of a porphyrin-loaded tumor [2].

Porphyrin and/or metalloporphyrin mediated cleavage of nucleic acids occurs via oxidative attack on the sugar moiety [3, 4], nucleobase modifications, which lead to strand scission [5], or by a photoinduced mechanism involving either the porphyrin excited states or singlet oxygen [6, 7]. Further, porphyrin-induced changes of DNA conformation could allow for the specific probing of DNA structure [8]. Not surprisingly, developments in this area are predicated upon a detailed understanding of the porphyrin-DNA binding mechanism.

Three generalized binding modes have been described for the interaction of cationic porphyrins with DNA: i) intercalation, ii) outside groove binding and iii) outside binding with self-stacking, a mode that leads to the production of organized porphyrin structures on the DNA exterior [9-12]. Complexation to nucleic acids has been examined for a limited number of cationic porphyrins so far. In this respect, purposeful

\footnotetext{
†E-mail: kubat@jh-inst.cas.cz
}

functionalization of the porphyrin moiety offers compounds differing in charge, substituents and hydrophobicity. Lipophilic substituents may make it easier for the porphyrin to pass through or accumulate in biomembranes. It may change the site recognition properties and the affinity of porphyrins to nucleic acids.

Recently we synthesized tetratolylporphyrin derivatives with phosphonium, ammonium and sulfonium groups and we were interested in how the different number and structure of the solubilizing groups affects their physical and chemical properties and binding to DNA [13-15]. The particular sensitizers reported in this paper are derivatives of meso-tetraphenylporphyrin, which is itself known to be a good sensitizer with high quantum yield of singlet oxygen $\left(\Phi_{\Delta}=0.34\right.$ 0.87) [16]. Two novel porphyrin derivatives substituted by guanidiniocarbonyl (I) and monocyclic guanidine (II) groups have long cationic "tentacles" that should allow formation of complexes with negatively charged biopolymers like nucleic acids. The cationic centers are insulated from the porphyrin ring and thus have minimal influence on the electron density in the $\pi$-system of the porphyrin chromophore. From a design perspective, these porphyrins were expected to display excellent photophysical properties similar to parent tetraphenylporphyrin, yet be water-soluble and exhibit binding affinities for DNA 

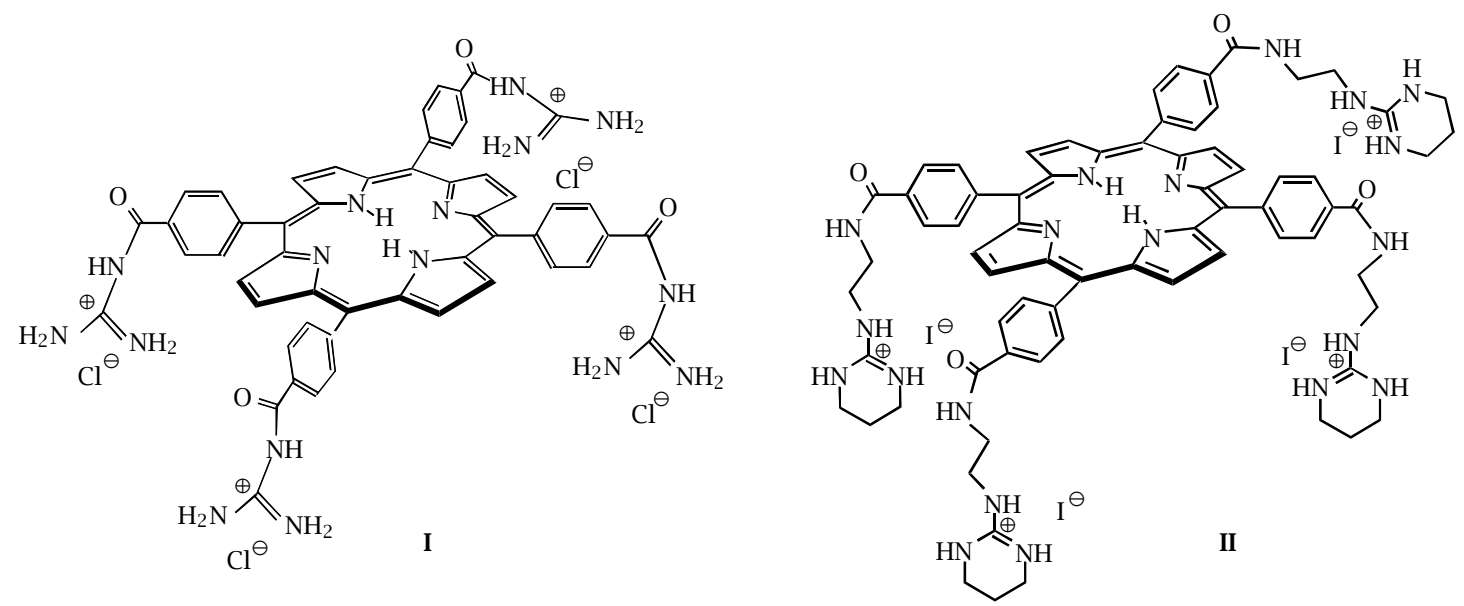

Scheme 1. Structures of I and II with guanidiniocarbonyl and monocyclic guanidine substituents, respectively.

augmented by the charged substituents. Physicochemical and photophysical properties of I, II and their complexes with DNA were measured and compared with behavior of cationic meso-tetratolylporphyrin derivatives [13-15].

\section{EXPERIMENTAL}

5, 10, 15, 20-Tetrakis( guanidiniocarbonyl)porphyrin I was synthesized from corresponding ester by reaction with guanidine hydrochloride and sodium methanolate in methanol. 5,10,15,20-Tetrakis(monocyclic guanidine)porphyrin II was prepared by coupling of porphyrin carboxylic acid or acylchloride with aminoethylguanidine derivative under standard amide bond formation protocol [17, 18]. The porphyrins I and II were characterized by elemental analysis, UV/Vis, ${ }^{1} \mathrm{H}$ NMR, ${ }^{13} \mathrm{C}$ NMR, FAB and MALDI TOF mass spectrometry. The pure porphyrins were obtained by crystallization from methanol-dichloromethane mixture and the purity was verified by HPLC analysis. The stock porphyrin solutions(100-200 $\mu \mathrm{M})$ were prepared in methanol (Riedel-de Haën, HPLC grade) and diluted with water, phosphate buffer, or methanol prior to use. The concentration of calf thymus double-stranded DNA (Sigma), calculated in base pairs, was determined spectrophotometrically using molar absorptivity $\varepsilon_{260}=1.31 \times 10^{4} \mathrm{M}^{-1} \mathrm{~cm}^{-1}$ [19]. Experiments with different porphyrin/DNA molar concentration ratios $(R)$ were performed in $20 \mathrm{mM}$ phosphate buffer ( $\mathrm{pH} 7.0)$ and $100 \mathrm{mM}$ sodium chloride at room temperature $\left(25^{\circ} \mathrm{C}\right)$ in $1 \times 1 \mathrm{~cm}$ quartz or plastic cells. Solutions of $\mathbf{I}$ and II $(1-5 \mu \mathrm{M})$ were titrated by addition of aliquots of DNA and equilibrated for $5 \mathrm{~min}$ before measurement. UV/Vis absorption spectra were measured on a Perkin Elmer Lambda 19 spectrophotometer.

The laser kinetic spectrometer (Applied Photophysics, UK) as well as the details of measurement have been described elsewhere [13]. A Lambda Physik FL 3002 dye laser $\left(\lambda_{\mathrm{exc}}=415 \mathrm{~nm}\right.$, pulse length $28 \mathrm{~ns}$, output $1-5 \mathrm{~mJ} /$ pulse) was used for production of the triplet states. The porphyrin triplets were probed at $445 \mathrm{~nm}$ using a $250 \mathrm{~W}$ Xe lamp equipped with a pulse unit and a R928 photomultiplier (Hamamatsu).

Time-resolved near-infrared luminescence of singlet oxygen $\mathrm{O}_{2}\left({ }^{1} \Delta_{\mathrm{g}}\right)$ at $1270 \mathrm{~nm}$ was monitored with a Ge diode (Judson J16-8SP, USA) in conjunction with a $1270 \mathrm{~nm}$ interference filter. The quantum yields of singlet oxygen $\Phi_{\Delta}$ were estimated by the comparative method using 5,10,15,20-tetrakis(4-sulfonatophenyl)porphyrin as a standard $\left(\Phi_{\Delta}=0.62\right.$ [16]) at excitation energy $50-380 \mu \mathrm{J}$. In this energy region the intensity of a luminescence signal is proportional to the incident energy. Where appropriate, oxygen was removed from solutions via purging with argon.

\section{RESULTS AND DISCUSSION}

\subsection{Aggregation of I and II in aqueous solu-}

tions. The porphyrins I and II (Scheme 1) show typical monomeric spectra in methanol with intensive absorption maximum at $415 \mathrm{~nm}$ (Soret band) and four visible Q bands at longer wavelengths (Table 1). The solutions were investigated up to $5 \mu \mathrm{M}$ and it was found that they obey Lambert-Beer's law. All porphyrins are well soluble in water with some degree of aggregation indicated by a broadening of the Soret bands (Figure 1) and by deviations from the Lambert-Beer law.

I is predominantly monomeric in aqueous solutions (Figure 1(a)) at low ionic strength $(0-500 \mathrm{mM} \mathrm{NaCl})$. More extended aggregation of I occurs at concentrations of $\mathrm{NaCl}$ above $1 \mathrm{M}$. Aggregation is accompanied by decreasing and broadening of the Soret band. Transient triplet-triplet absorption spectra of I are broad with the absorption maximum at $445 \mathrm{~nm}$ that is typi- 
Table 1. UV/Vis absorption bands of I and II, and molar absorption coefficients $\varepsilon$ in parentheses.

\begin{tabular}{|c|c|c|c|c|c|c|}
\hline \multicolumn{7}{|c|}{$\lambda_{\max }[\mathrm{nm}]\left(\varepsilon\left[\mathrm{M}^{-1} \mathrm{~cm}^{-1}\right]\right)$} \\
\hline \multirow[b]{2}{*}{ I/MeOH } & \multirow{2}{*}{$\frac{R}{-}$} & \multirow{2}{*}{$\begin{array}{l}\text { Soret band } \\
415\left(2.0 \times 10^{5}\right)\end{array}$} & \multicolumn{4}{|c|}{ Q bands } \\
\hline & & & $512\left(8.6 \times 10^{3}\right)$ & $548\left(3.6 \times 10^{3}\right)$ & $590\left(2.5 \times 10^{3}\right)$ & $646\left(1.8 \times 10^{3}\right)$ \\
\hline II/MeOH & - & $415\left(2.2 \times 10^{5}\right)$ & $512\left(8.8 \times 10^{3}\right)$ & $548\left(4.6 \times 10^{3}\right)$ & $590\left(3.1 \times 10^{3}\right)$ & $646\left(2.3 \times 10^{3}\right)$ \\
\hline I/buffer $\left({ }^{\mathrm{a}}\right)$ & - & $414\left(1.5 \times 10^{5}\right)$ & $516\left(5.8 \times 10^{3}\right)$ & $553\left(3.5 \times 10^{3}\right)$ & $585\left(2.8 \times 10^{3}\right)$ & $643\left(2.0 \times 10^{3}\right)$ \\
\hline II/buffer $\left({ }^{\mathrm{a}}\right)$ & - & $403,(416), 425\left(^{b}\right)$ & 521 & 556 & 596 & 650 \\
\hline I/ct DNA( $\left(^{\mathrm{a}}\right)$ & 0.025 & $414\left(1.3 \times 10^{5}\right)$ & $516\left(5.0 \times 10^{3}\right)$ & $553\left(2.9 \times 10^{3}\right)$ & $585\left(2.7 \times 10^{3}\right)$ & $643\left(1.5 \times 10^{3}\right)$ \\
\hline II $/$ ct DNA $\left({ }^{a}\right)$ & 0.020 & $403,(416), 425\left(^{b}\right)$ & 521 & 556 & 596 & 650 \\
\hline
\end{tabular}

(a) $20 \mathrm{mM}$ phosphate buffer, pH 7.0, $100 \mathrm{mM} \mathrm{NaCl}$.

(b) Splitted to at least three subband due to extensive aggregation.

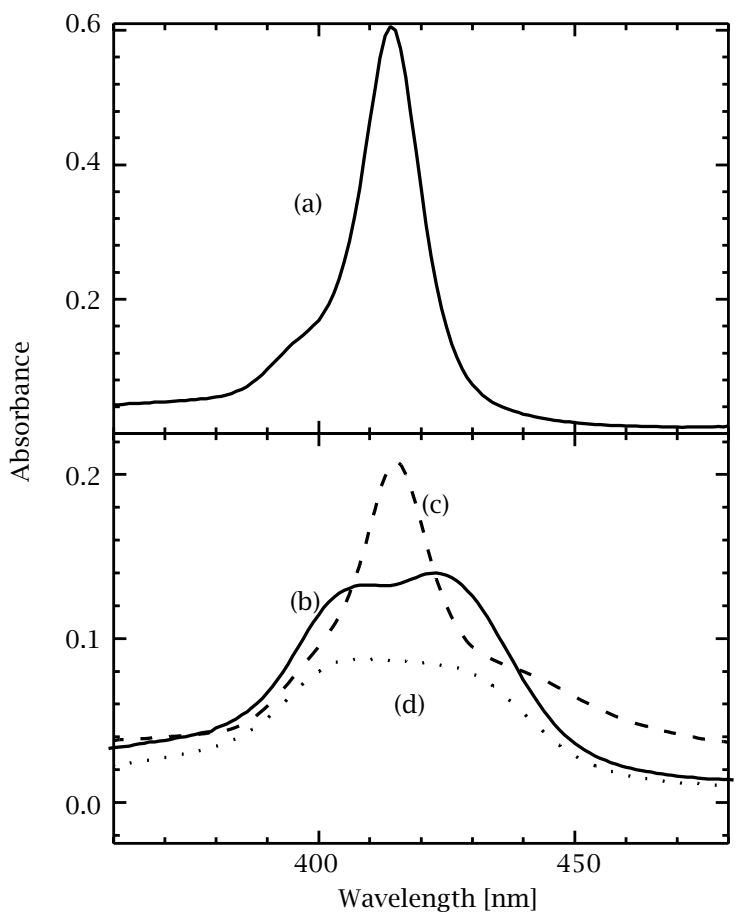

Figure 1. Soret band of $3.6 \mu \mathrm{M} \mathrm{I}, 100 \mathrm{mM} \mathrm{NaCl}, 25^{\circ} \mathrm{C}($ a), $2.5 \mu M$ II, $100 \mathrm{mM} \mathrm{NaCl}, 25^{\circ} \mathrm{C}(b), 2.5 \mu \mathrm{M}$ II, $100 \mathrm{mM} \mathrm{NaCl}$, $85^{\circ} \mathrm{C}(\mathrm{c}), 2.5 \mu \mathrm{M} \mathrm{II}, 670 \mathrm{mM} \mathrm{NaCl}, 25^{\circ} \mathrm{C}(\mathrm{d}), 20 \mathrm{mM}$ phosphate buffer, pH 7.0.

cal for monomeric porphyrins (Figure 2(a)). The triplet states of I decay monoexponentially (Figure 2(b), Table 2). They are effectively quenched by molecular oxygen (Table 2) with the diffusion-controlled bimolecular rate constant of $\sim 2 \times 10^{9} \mathrm{lmol}^{-1} \mathrm{~s}^{-1}$ producing singlet oxygen. We found high quantum yield of singlet oxygen $\left(\Phi_{\Delta}=0.67\right.$, Figure $\left.3(\mathrm{a})\right)$ of I that is comparable with $\Phi_{\Delta}=0.62$ for 5,10,15,20-tetrakis(4-sulfonatophenyl)porphyrin that is known as an efficient sensitizer in human medicine [20].

The monocyclic guanidine groups on the porphyrin periphery of II impose a strong tendency to form extended aggregates in aqueous solutions. This behav-

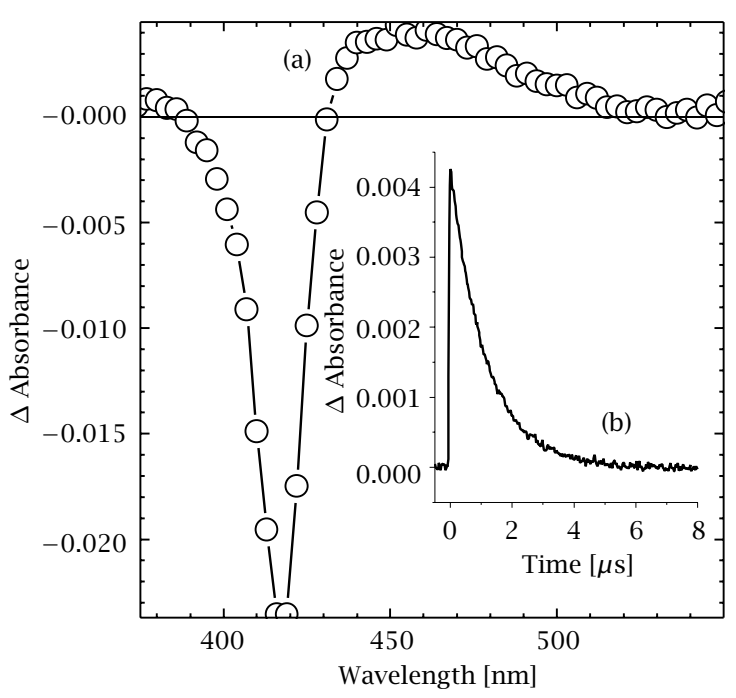

Figure 2. Triplet-triplet transient absorption spectrum of $2.0 \mu \mathrm{M}$ I recorded $100 \mathrm{~ns}$ after the excitation pulse (a) and its monoexponential decay curve at $445 \mathrm{~nm}$ (b). Excitation wavelength $415 \mathrm{~nm}$, air-saturated $20 \mathrm{mM}$ phosphate buffer, $\mathrm{pH} 7.0$, average from 16 traces.

ior is reflected by marked broadening and splitting of the Soret band into at least three individual bands (Figure 1(b)). The complex Soret band can be resolved into individual subbands using a Voigt function (convolution of a Lorenzian function with a Gaussian function) [21]. Relative intensities of the Soret subbands depend on $\mathrm{pH}$, porphyrin concentration, degree of aging and temperature. II is predominantly monomeric above $60^{\circ} \mathrm{C}$ (Figure $1(\mathrm{c})$ ). The monomer has Soret band at $416 \mathrm{~nm}$ (Table 1). However, under these conditions II is not chemically stable and decomposes.

Aggregation of II is strongly facilitated at higher ionic strengths (Figure 1(d)) because the counteranions presumably compensate a high positive charge density of extended aggregates. Two generalized aggregate structures, namely $\mathrm{H}$-aggregates and J-aggregates $[22,23]$, can be recognized (Figure 1, Table 1). The 
Table 2. Lifetimes of the triplet states of monomeric I and II recorded at $445 \mathrm{~nm}$ in the absence of oxygen $\boldsymbol{\tau}_{\mathrm{T}}$ (He) and in aerated solutions $\tau_{\mathrm{T}}$ (air), the quantum yields of singlet oxygen $\Phi_{\Delta}$ and effects of binding to calf thymus DNA are compared with cationic 5,10,15,20-tetrakis(4-N-methylpyridyl)porphyrin (TMPyP) [14, 16]. Values are given with an accuracy of $15 \%$.

\begin{tabular}{|c|c|c|c|c|c|c|}
\hline & \multicolumn{3}{|c|}{ Phosphate buffer } & \multicolumn{3}{|c|}{ Calf thymus DNA } \\
\hline & $\tau_{\mathrm{T}}(\mathrm{He})[\mu \mathrm{s}]$ & $\tau_{\mathrm{T}}(\operatorname{air})[\mu \mathrm{s}]$ & $\Phi_{\Delta}$ & $\begin{array}{c}\boldsymbol{T}_{\mathrm{T}}(\mathrm{He})[\mu \mathrm{s}] \\
\end{array}$ & $\tau_{\mathrm{T}}(\operatorname{air})[\mu \mathrm{s}]$ & $\Phi_{\Delta}$ \\
\hline I & 190 & 1.7 & $0.67\left(^{b}\right)$ & 192 & 1.7 & $0.63\left(^{b}\right)$ \\
\hline II & $-\left({ }^{\mathrm{a}}\right)$ & $-\left({ }^{\mathrm{a}}\right)$ & $<0.01\left({ }^{b}\right)$ & 1400 & 69 & $<0.01\left(^{\mathrm{b}}\right)$ \\
\hline TMPyP & 150 & 1.9 & 0.74 & 1700 & 24 & - \\
\hline
\end{tabular}

(a) No signal due to extensive porphyrin aggregation.

(b) Calculated by a comparative method using 5,10,15,20-tetrakis(4-sulfonatophenyl) porphyrin as a standard $\left(\Phi_{\Delta}=0.62\right)[16]$.

appearance of a blue- shifted band at $403 \mathrm{~nm}$ indicates the presence of sandwich-type aggregates $(\mathrm{H}-$ aggregates). In this case the transition dipole moments of interacting monomer units are perpendicular to the line connecting the porphyrin centers. A red-shifted band at $425 \mathrm{~nm}$ can be attributed to the mixture of structures with an angle between the transition dipole moments and the line connecting the centers of the monomer units in the range $0-54.7^{\circ}$ (J-aggregates). Because relaxation of the excited states of aggregates occurs predominantly via nonradiative processes the concentration of the triplet states of II after excitation is strongly reduced when compared with the corresponding monomer. Consequently, the intensity of singlet oxygen luminescence cannot be separated from instrumental noise (Figure 3(b)) and it is under detection limit of the instrument. From it follows that the quantum yield $\Phi_{\Delta}$ of II in aqueous solution is less than 0.01 (Table 2). This is in accordance with literature data on aggregated forms of porphyrins [24].

3.2. The porphyrins I and II in the presence of DNA. The electronic absorption spectra of I and II were measured in the range of $250-800 \mathrm{~nm}$ in the presence of calf thymus DNA as a function of $R=1.00-0.02$.

The Soret and Q-bands of I are not influenced by the presence of DNA. In general, the binding of porphyrins with the nucleic acid is associated with a red shift of the Soret band. For example, meso-tetratolylporphyrins bearing $\mathrm{N}^{+}\left(\mathrm{CH}_{3}\right)_{3},-(1 \text {-pyridinium })^{+}[13],-\mathrm{P}^{+}\left(\mathrm{CH}_{3}\right)_{3}$ and $-\mathrm{P}^{+}\left(\mathrm{CH}_{3}\right)_{2}$ (phenyl) [15] substituents are redshifted by 6-8 nm. Transient spectroscopy supports results of steady-state UV/Vis absorption spectra. Triplettriplet absorption spectra and lifetime of the triplet states of I are not affected by DNA (Table 2). The quantum yield $\Phi_{\Delta}$ of I does not depend on the concentration of DNA within experimental error $( \pm 15 \%$, Table 2). Therefore, we do not have spectroscopic evidence whether $\mathbf{I}$ is bound to DNA. Electrostatic attraction forces between cationic sites of porphyrins and the negatively charged phosphate backbone of DNA are crucial for the binding phenomena and influ-

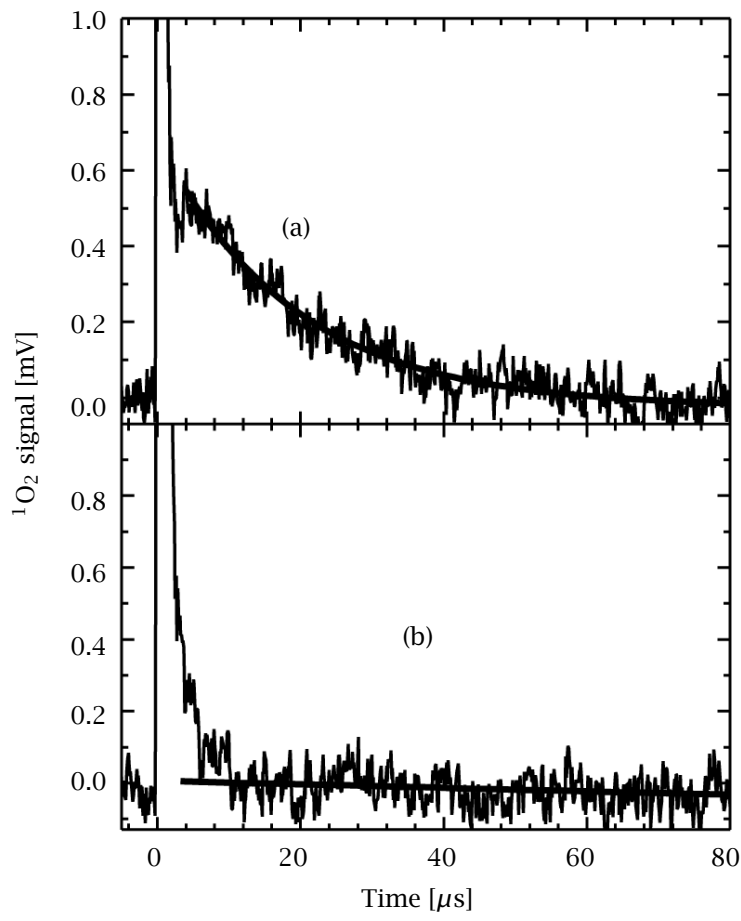

Figure 3. Luminescence of singlet oxygen at $1270 \mathrm{~nm}$ formed by quenching of the triplet states of $\mathbf{I}(a)$ and $\mathbf{I I}$ (b) with dissolved oxygen in air-saturated aqueous solution. Matching absorbance at the excitation wavelength of $413 \mathrm{~nm}$ : $A_{413}=0.213$, average from 1000 traces, $5 \mathrm{mM}$ phosphate buffer, pH 7.0 contains $70 \% \mathrm{D}_{2} \mathrm{O}$ and $30 \% \mathrm{H}_{2} \mathrm{O}$ in order to increase lifetime of singlet oxygen.

ence the final arrangement of porphyrins units [13]. As guanidine groups bear the positive charge their interaction with phosphates is evident and have to be taken into consideration. However, the contact of the porphyrin moiety with the DNA backbone appears to be so distant that the electronic energy levels of the porphyrin are not perturbed by stacking with nucleobases.

The presence of DNA influences the driving forces 
for self-aggregation of II due to the negatively charged backbone phosphates. The absorption spectra of II in the presence and absence of DNA show that selfaggregation is accelerated by DNA, but ratio between various types of aggregates after 5 minutes of equilibration does not depend on DNA concentration and it is controlled by peripheral substitution of II and ionic strength. Extensive aggregation and high kinetic stability of aggregates do not allow binding of the porphyrin monomer from the solution. This is supported by the fact that $\Phi_{\Delta}$ is more than two orders of magnitude lower in aqueous solution in the presence or absence of DNA than in methanol, where II is predominantly monomeric. In summary, the high tendency of II to form aggregates in aqueous solutions renders the monomer unavailable for binding to DNA. Similar behavior is observed for highly aggregated meso-tetratolyporphyrins with hydrophobic substituents like $-\mathrm{P}^{+}(\text {phenyl })_{3},-\mathrm{S}^{+}\left(\mathrm{CH}_{3}\right)_{2}$ or $-\mathrm{SC}\left(\mathrm{NH}_{2}\right)_{2}{ }^{+}$that spontaneously assemble into chiral aggregates on the exterior of a double-helical DNA template $[13,14]$.

On the other hand, when small aliquot of the monomer of II in methanol is added to DNA solutions (the methanol content did not exceed 5\% v.v.), the binding phenomena is evidenced by the appearance of small concentrations of the monomer triplet states in transient spectroscopy. The lifetime of the triplet states of II is 7-8 times longer than triplet states of I (Table 2). It is known that porphyrins bound to DNA exhibit considerable lengthening of the triplet state lifetimes [13, 15]. Hence the lifetime of the triplet states confirms that the monomer of II is bound preferably on the external surface of the nucleic acid. Intercalation of II between base pairs of DNA is excluded because long "tentacles" with the bulky substituents impose steric obstacles. But still the concentration of the triplet states is so low that production of singlet oxygen is below detection limit similarly to aqueous solutions of II (Table 2).

\section{ACKNOWLEDGEMENT}

This research was supported by the Grant Agency of the Czech Republic (No.203/01/0634 and 203/99/1163). The Howard Hughes Medical Institute (grant No. 74195541101 to V.K.) and Hans Fischer Foundation grant (to V.K. and F.P.S.) are gratefully acknowledged.

\section{References}

[1] R. Bonnet, Chem. Soc. Rev. 24 (1995), 19.

[2] C. J. Gomer, Photodynamic therapy. Pergamon Press, 2000.

[3] B. Meunier, Chem. Rev. 92 (1992), 1411.

[4] W. Knapp Pogozelski and T. D. Tullius, Chem. Rev. 98 (1998), 1089.

[5] C. J. Burrows and J. G. Muller, Chem. Rev. 98 (1998), 1109.

[6] B. Armitage, Chem. Rev. 98 (1998), 1171.

[7] J. L. Ravanat, P. Di Mascio, G. R. Martinez, M. H. G. Medeiros, and J. Cadet, J. Biol. Chem. 275 (2000), 40601.

[8] E. Di Mauro, R. Saladino, P. Tagliatesta, V. De Sanctis, and R. Negri, J. Mol. Biol. 282 (1998), 43.

[9] H. J. Schneider and M. Wang, J. Org. Chem. 59 (1994), 7464.

[10] P. Lugo-Ponce and D. R. McMillin, Coord. Chem. Rev. 208 (2000), 169.

[11] R. F. Pasternack, E. J. Gibs, and J. J. Villafranca, Biochemistry 22 (1983), 2406.

[12] F. J. Vergeldt, R. B. M. Koehorst, A. van Hoek, and T. J. Schaafsma, J. Phys. Chem. 99 (1995), 4397.

[13] P. Kubát, K. Lang, P. Anzenbacher, K. Jursíková, V. Král, and B. Ehrenberg, J. Chem. Soc. Perkin Trans 1 (2000), 933.

[14] K. Lang, P. Anzenbacher Jr., P. Kapusta, V. Král, P. Kubát, and D. M. J. Photochem. Photobiol. B 57 (2000), 51.

[15] P. Kubát, K. Lang, P. Anzenbacher, and V. Král, J. Phys. Chem. B, submited.

[16] F. Wilkinson, V. P. Helman, and A. B. Ross, J. Phys. Chem. Ref. Data 22 (1993), 113.

[17] C. Schmuck, Chem.-Eur. J. 6 (2000), 709.

[18] V. Král and F. P. Schmidtchen, will be published.

[19] R. R. Wells, J. E. Larson, R. C. Grant, B. E. Shortle, and C. R. Cantor, J. Mol. Biol. 54 (1970), 465.

[20] M. Lapeš, J. Petera, and M. Jirsa, J. Photochem. Photobiol. B 36 (1996), 205.

[21] A. Cupane, M. Leone, L. Cordone, H. Gilch, W. Dreybrodt, E. Unger, and R. Schweitzer-Stenner, J. Phys. Chem. 100 (1996), 14192.

[22] P. W. Bohn, Ann. Rev. Phys. Chem. 44 (1993), 37.

[23] R. F. Khairutdinov and N. Serpone, J. Phys. Chem. B 103 (1999), 761.

[24] F. Richelli, J. Photochem. Photobiol. B 29 (1995), 109. 


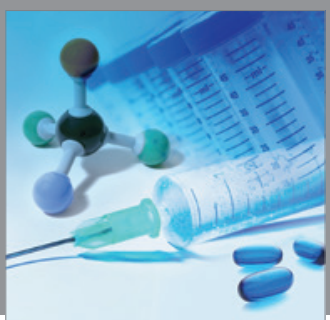

International Journal of

Medicinal Chemistry

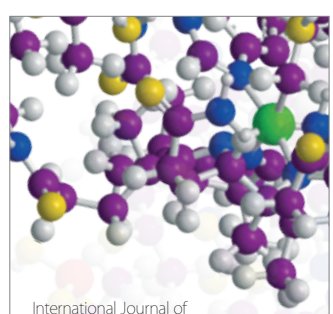

Carbohydrate Chemistry

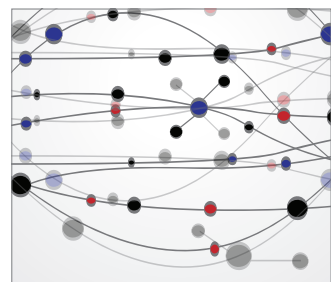

The Scientific World Journal
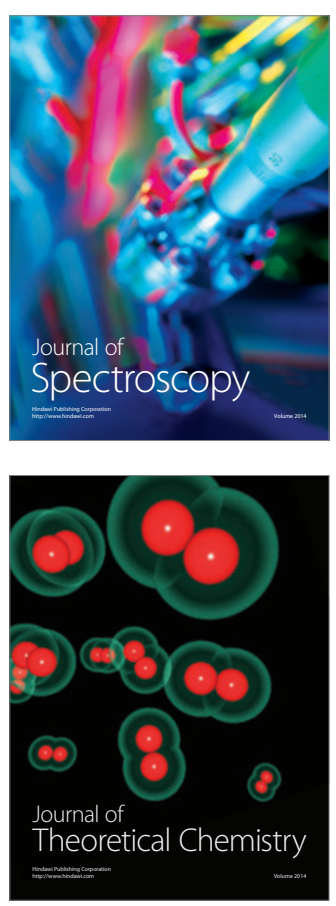
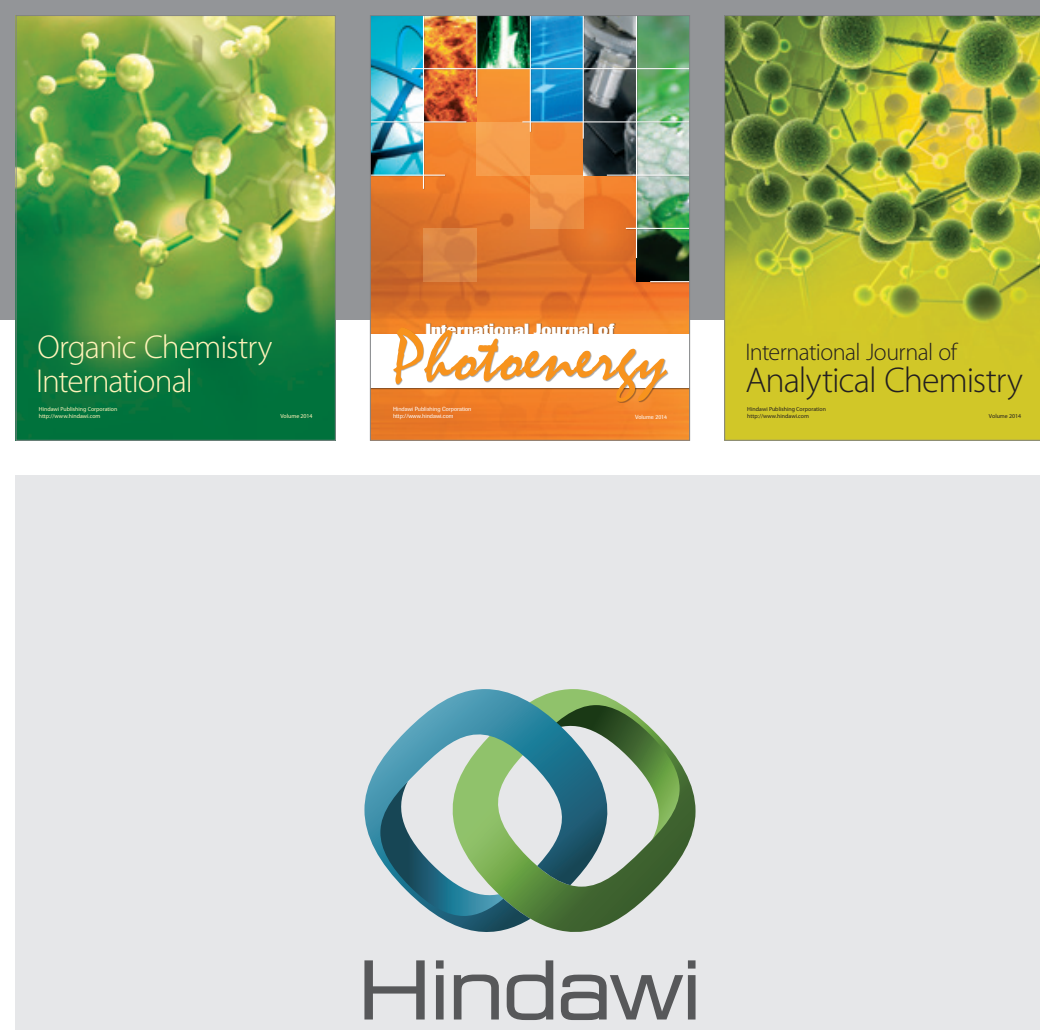

Submit your manuscripts at

http://www.hindawi.com
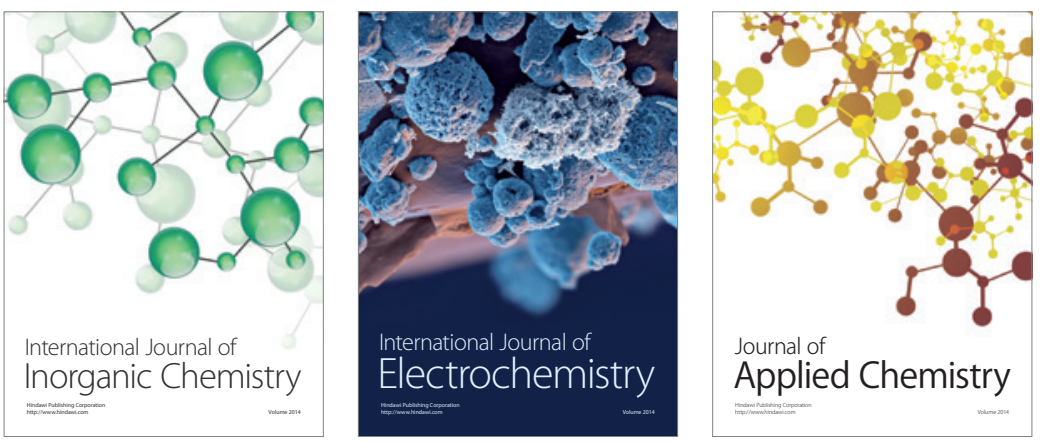

Journal of

Applied Chemistry
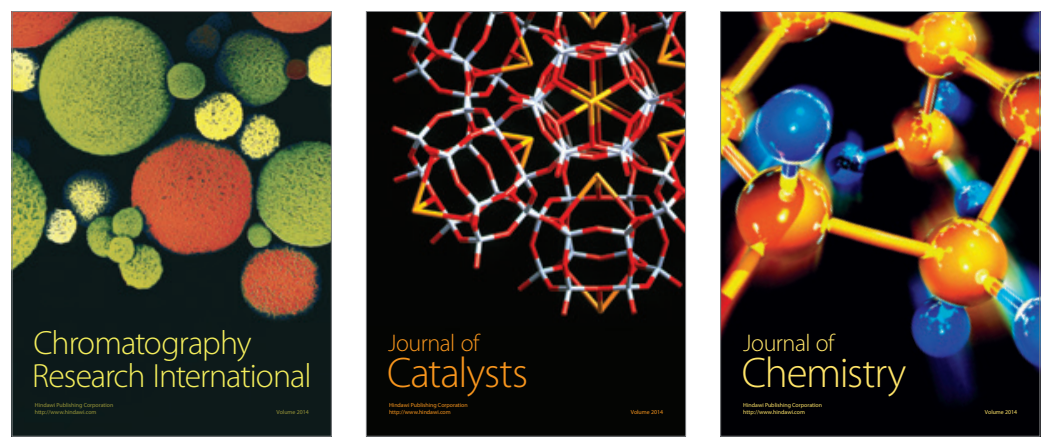
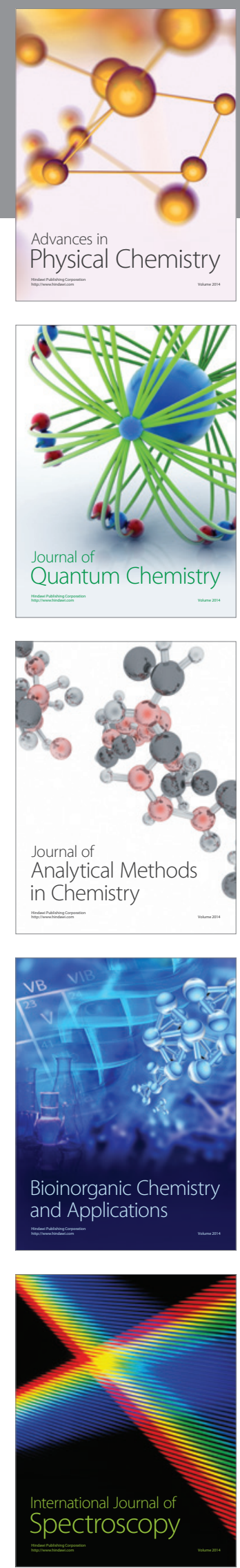